\title{
Validation of Satellite Observations of Storm Damage to Cropland with Digital Photographs
}

\author{
KEVIN GALLO \\ NOAA/NESDIS/Center for Satellite Applications and Research, College Park, Maryland \\ PHILIP SCHUMACHER \\ NOAA/NWS Weather Forecast Office, Sioux Falls, South Dakota \\ JOSH BOUSTEAD ${ }^{\mathrm{a}}$ \\ NOAA/NWS Weather Forecast Office, Omaha, Nebraska \\ Alex Ferguson \\ NOAA/NWS Weather Forecast Office, Amarillo, Texas
}

(Manuscript received 12 April 2018, in final form 13 February 2019)

\begin{abstract}
Severe storm events that include hail and wind often cause widespread contiguous swaths of damage; however, their occurrence is typically documented at individual and disjointed locations. Satellite-derived products, such as the normalized difference vegetation index (NDVI), can provide a more spatially uniform look at the extent of these events, particularly in rural or remote areas. The utility of incorporating satellitebased products into the damage identification and documentation process was assessed through highresolution ground surveys, which included digital photographs, to classify three levels of cropland damage for three severe hail/wind events occurring in the Great Plains during the summer of 2014. Pre- and postevent NDVI values at the photograph locations were calculated using surface reflectance values from the Moderate Resolution Imaging Spectroradiometer (MODIS) and grouped by damage severity level. In general, more severe crop damage displayed a lower NDVI in the postevent imagery compared to undamaged crops. Additionally, the difference in the median NDVI between the pre- and postevent images was statistically significant between the damage categories with similar trends observed across the three summertime events. Thus, satellite-derived products should be promoted as a valuable tool for the initial assessment of damage severity and extent to agricultural crops and should be integrated when possible into the current hazard documentation process as a supplement to the currently available point-based observations of storm damage.
\end{abstract}

\section{Introduction}

Damaging winds and hail associated with severe thunderstorms in the United States annually cause millions of dollars in damage to property and agricultural crops. Hundreds of hectares of crops can be destroyed by individual storms (e.g., Stout et al. 1960; Changnon et al. 2009), resulting in substantial losses to impacted farms. Multiple

\footnotetext{
${ }^{a}$ Current affiliation: PEMDAS Technologies and Innovations, Alexandria, Virginia.
}

Corresponding author: Kevin Gallo, kevin.p.gallo@noaa.gov hail events each year may be anticipated within several regions of the United States (Cintineo et al. 2012). Hail damage estimated in 2017 (most recent year available) included property damage of over $\$ 1.72$ billion and crop damage of over $\$ 590$ million dollars (NOAA 2018a). Hail damage from events during 2015-17 was 3 times more expensive than damage associated with other convective storm events (NOAA 2018b). Damage associated with these and other events is documented by the National Weather Service (NWS) through the Storm Data publication (NOAA 2018c) that is prepared from data included in the NOAA Storm Events Database (NOAA 2018d). The database includes poststorm summaries, is 
quality controlled, and is considered the official source of storm damage and impacts. Storm report data are primarily obtained from the general public, trained observers, emergency managers, law enforcement officers, and the insurance industry (NOAA 2018e). Most of the property and crop loss values are estimates of insured losses. Additionally, for each event, the database includes location (latitude and longitude), start and end times (if available), pathlength and width (for tornado events), number injuries or fatalities, estimated monetary damage (dollars) to property and crops, and type of storm event (e.g., tornado, thunderstorm wind, lightning, and hail). For a small number of tornado and wind events, an NWS damage survey team documents damage associated with the storm, but most wind-driven hail or hail damage events are not surveyed.

One limitation associated with the information available from the Storm Events Database is that events that inherently affect a spatial region (storms typically cause damage of varying intensity over widespread areas) are observed and reported primarily for point-based locations. As shown in Fig. 1b of Gallo et al. (2012), and mentioned by Witt et al. (1998b), single-point observations made for storm events that include estimates of hail size and location do not readily provide the spatial extent of the event, or distribution of the intensity or damage of the event within the spatial boundaries. Spatial extent and varying severity of storm events would assist in poststorm assessments of storm event forecasts and validation of NWS-issued storm warnings. Additional limitations related to the use of data available from Storm Data are discussed by Witt et al. (1998b), among others.

An experimental effort to provide a significant enhancement to the current observations included more comprehensive ground-based surveys (Ortega et al. 2009); however, these surveys were limited to specifically selected storm events and this effort ended in 2015 (Ortega 2018). Additionally, as pointed out by Blair et al. (2017), the density of available roads can result in a considerable area that is not accessible in studies of hail events. Blair et al. (2017) found that over $30 \%$ of the hail events included in their study were not documented within the Storm Data reports and suggested satellite-derived hail swaths of damaged vegetation as a potential alternative to ground surveys in similar studies.

The impact of hail on vegetated land surfaces as observed with satellites has been previously documented (e.g., Klimowski et al. 1998; Bentley et al. 2002; Yuan et al. 2002; Parker et al. 2005; Segele et al. 2005; Jedlovec et al. 2006; Gallo et al. 2012; Molthan et al. 2013; Bell and Molthan 2016). Several of these studies of hail events (e.g., Parker et al. 2005; Gallo et al. 2012; Molthan et al. 2013; Bell and Molthan 2016), as well as tornadic events (e.g., Yuan et al. 2002; Molthan et al. 2014; Kingfield and de Beurs 2017), have included a satellite-derived normalized difference vegetation index (NDVI; Rouse et al. 1974) in their assessments of storm damage. Generally, decreased NDVI values were observed where vegetation damage was observed, compared to undamaged vegetation.

Klimowski et al. (1998) and Parker et al. (2005) evaluated satellite observations of hail event damage from general categorizations of the damage to vegetation based on assessment of a limited number of photographs. While radar-based products of the Maximum Expected Size of Hail (MESH; Witt et al. 1998a; Smith et al. 2016) and spatial extent of hail damage have been utilized in several studies of hail events (Gallo et al. 2012; Molthan et al. 2013; Bell and Molthan 2016) these radarbased products are not routinely archived network-wide for poststorm event assessments. Although a valuable tool, radar-based estimates of hail location are based on observations of the hail above the surface and may be displaced from the location where the hail is eventually deposited and observed on the land surface through public reports or satellite observations (Gallo et al. 2012).

The objective of this study is to use geotagged digital photographs of damage from surveys associated with three hail/wind-driven hail events (hereafter referred to as hail events) to assess the potential use of satellite observations to (i) distinguish general levels of damage to cropland and (ii) supplement the in situ (single-point) observations of hail damage documented in the Storm Events Database and included in the Storm Data publication.

\section{Methodology}

\section{a. Selected storm events}

Storm surveys for hail damage are not routinely conducted by the NWS. This study included three documented severe storm events (NOAA 2018d) that persisted at least $2 \mathrm{~h}$ and produced damaging winds and large hail.

The first event, 3 June 2014, involved a supercell that developed in southwestern South Dakota during the morning and moved southeastward through eastcentral Nebraska and into southwestern Iowa (Fig. 1). This storm had reported hail up to $10.8 \mathrm{~cm}$ (4.25 in.) in diameter, winds of $40.7 \mathrm{~m} \mathrm{~s}^{-1}$ (91 mph) and did noticeable damage to crops and buildings across eastcentral Nebraska and southwestern Iowa. This survey includes the portion of the storm damage that occurred between Uehling, Nebraska, and Missouri Valley, Iowa, from approximately 2030 to 2230 UTC.

The second event, 9 July 2014, involved a supercell that impacted portions of central and south-central Nebraska 
(a)

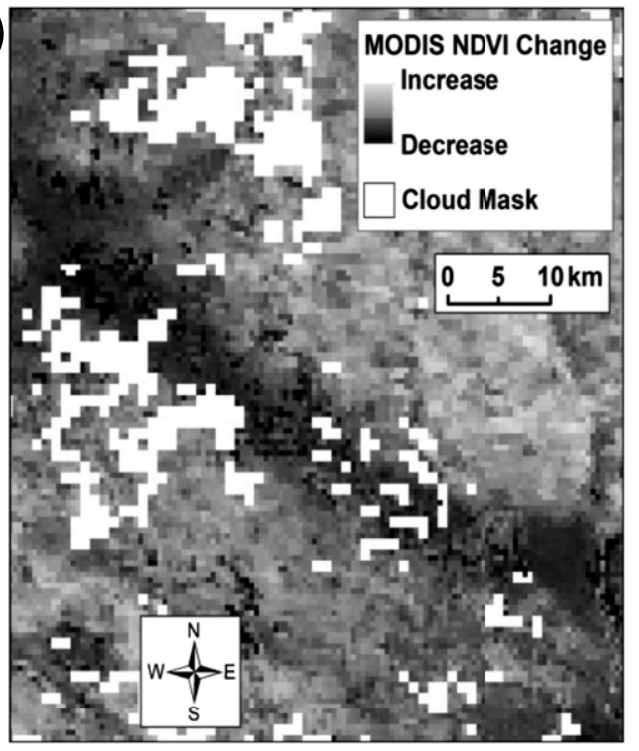

(b)

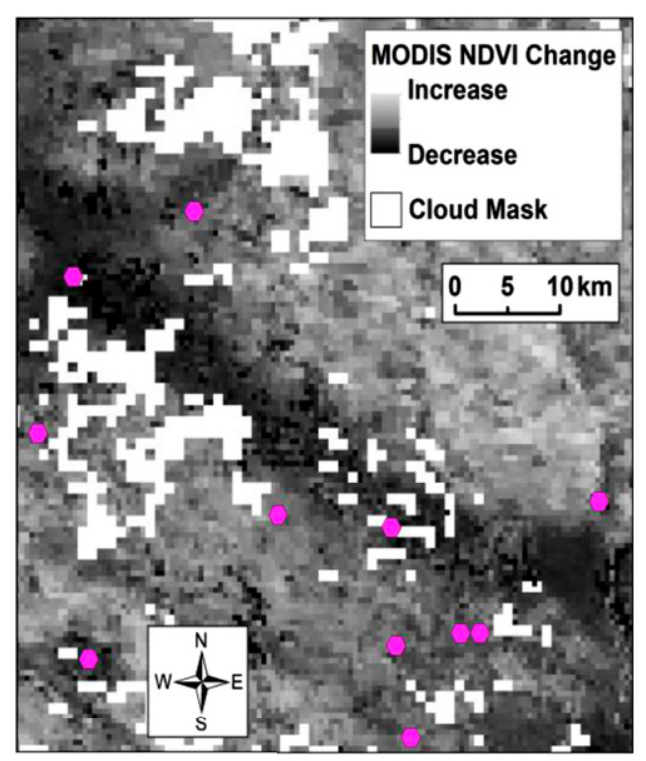

\section{(c)}

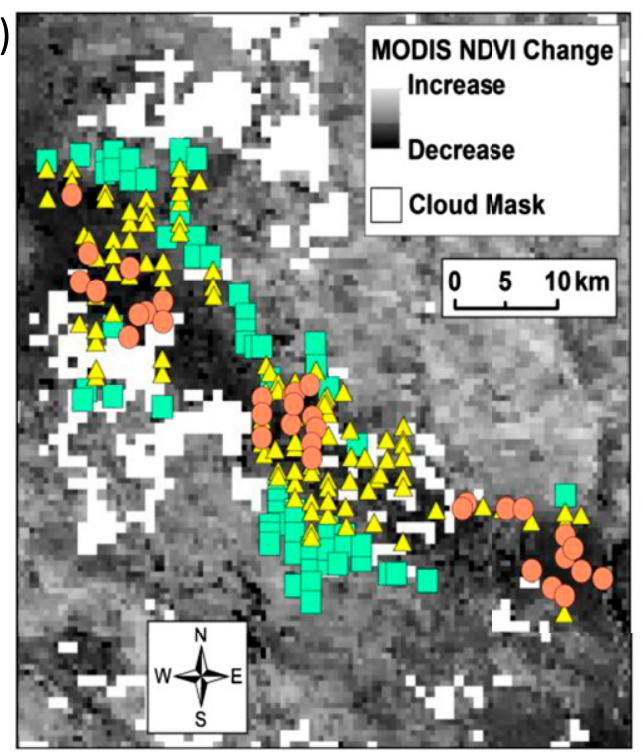

(d)

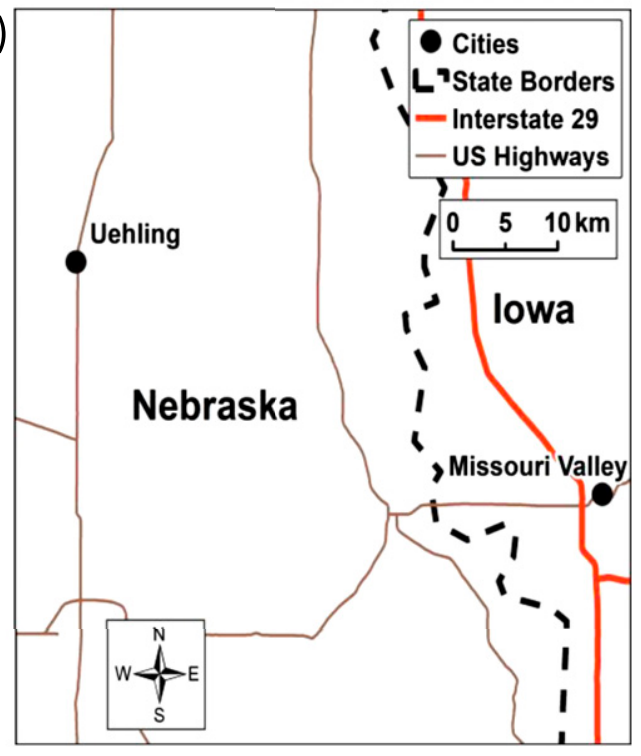

FIG. 1. (a) MODIS post- minus pre-event NDVI change, (b) with overlay (hexagons) of locations of observer reports of hail included in Storm Events Database (NOAA 2018d), (c) with overlay of damage levels determined by digital photographs, and (d) corresponding map of region for the 3 Jun 2014 event. Damage levels in (c) include No Damage (square symbol), Moderate Damage (triangle), and Severe Damage (circle). The nominal NDVI change values for this event ranged from -0.04 (lower $1 \%$ threshold value) to 0.52 (upper $99 \%$ threshold value).

(Fig. 2) from approximately 2130 to 0200 UTC. The supercell developed near Taylor, Nebraska, in northcentral Nebraska in the late afternoon. The supercell moved south-southeastward, crossing Interstate 80 near Gibbon, and weakened southwest of Hastings in the evening. This supercell was associated with reports of $7.0 \mathrm{~cm}$ (2.75 in.) hail and $38 \mathrm{~m} \mathrm{~s}^{-1}(85 \mathrm{mph})$ winds. A majority of the hail damage swath associated with this storm was included in the survey of this event.
The third event involved a supercell that formed northwest of White Lake, South Dakota, on 26 July 2014 and lasted from approximately 1430 to 1615 UTC. The storm tracked southeastward toward Tabor, South Dakota, before dissipating in northeastern Nebraska (Fig. 3). This storm included reports of up to $7.0 \mathrm{~cm}$ (2.75 in.) hail and $30 \mathrm{~m} \mathrm{~s}^{-1}(67 \mathrm{mph})$ winds. A majority of the hail swath associated with this storm was included in the damage survey for this event. For all three events 


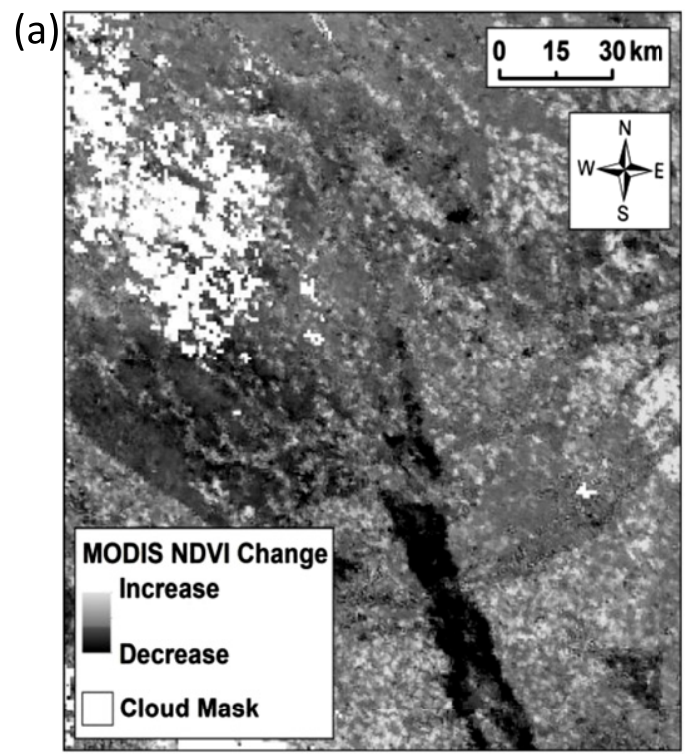

(b)

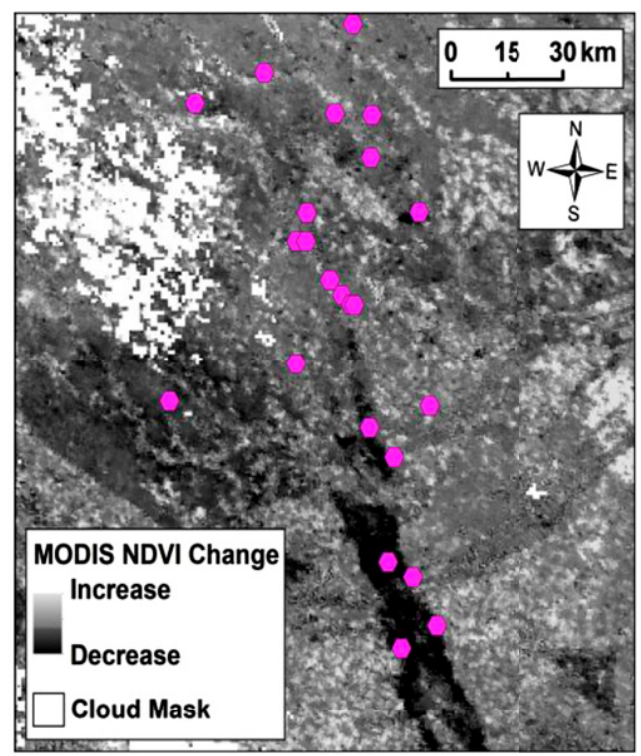

(c)

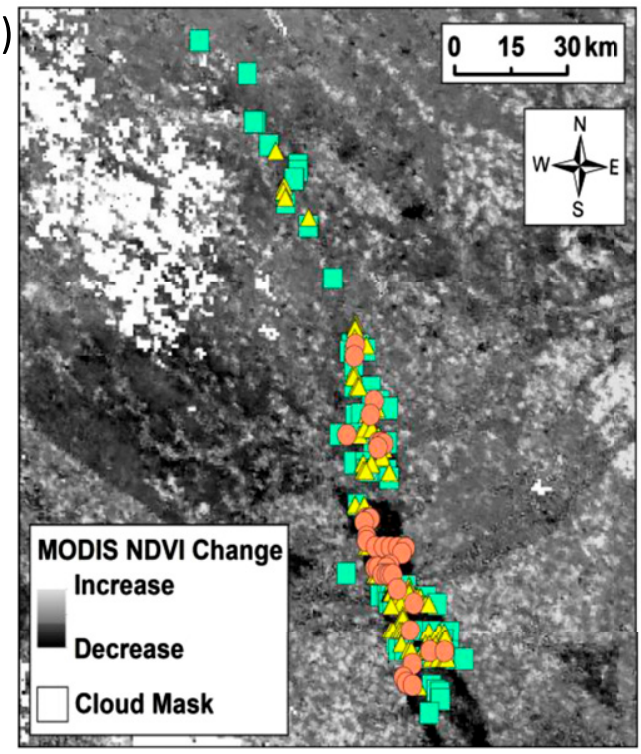

(d)

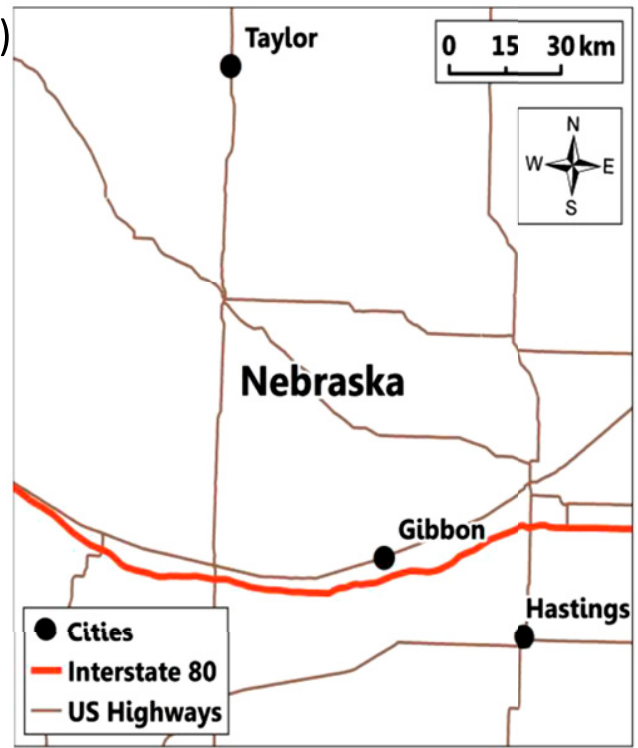

FIG. 2. As in Fig. 1, but for the $9 \mathrm{Jul} 2014$ event. The nominal NDVI change values for this event ranged from -0.34 (lower 1\% threshold value) to 0.44 (upper 99\% threshold value).

included in this study, the hail swaths extended over $50 \mathrm{~km}$ and were up to $10 \mathrm{~km}$ wide.

\section{b. Satellite data}

The NASA Terra Moderate Resolution Imaging Spectroradiometer (MODIS) MOD09GA version 006 daily surface reflectance product was obtained for dates prior to and after the examined hail events from the Land Processes Distributive Active Archive Center (LPDAAC 2018). These products were obtained through the LPDAAC Application for Extracting and Exploring Analysis Ready Samples (AppEEARS) web service (AppEEARS 2018).
The 500-m spatial resolution daily visible and near-IR surface reflectance data were provided as georegistered images reprojected to an Albers Conical Equal Area projection. MODIS data at the 500-m resolution were utilized, rather than available $250-\mathrm{m}$ data, in anticipation of the availability of similar products (at 500-m resolution) from the operational Visible Infrared Imaging Radiometer Suite (VIIRS) sensor. In addition to the surface reflectance data, an image was provided with the MOD09GA data that included cloud and cloud shadow information that was used to develop a cloud mask. The cloud mask was applied to the pre- and postevent 


\section{(a)}

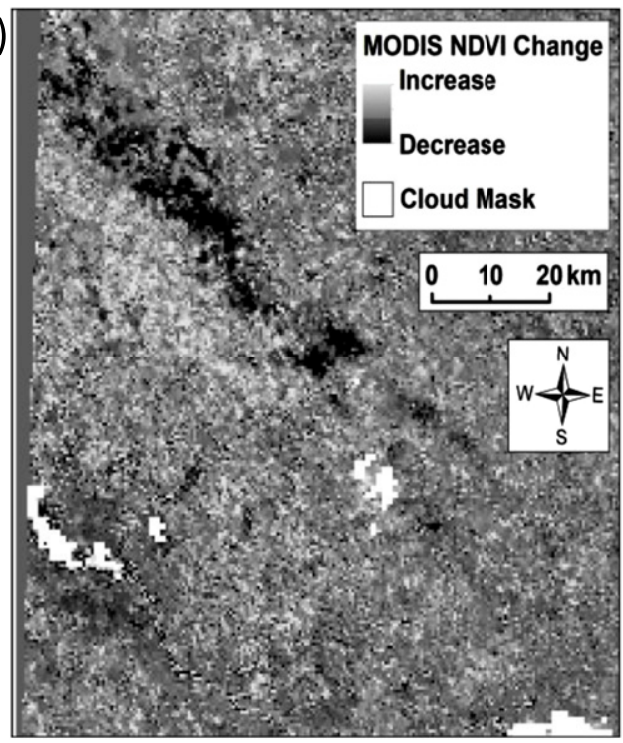

(c)

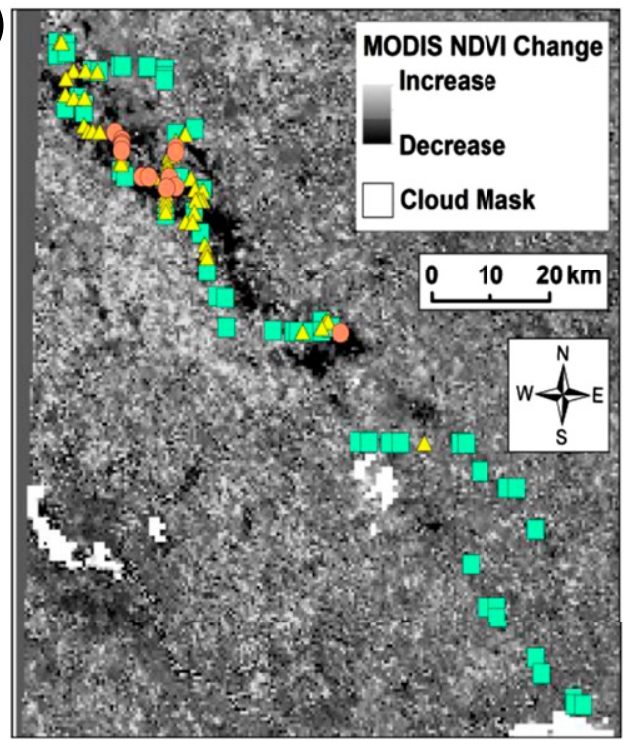

(b)

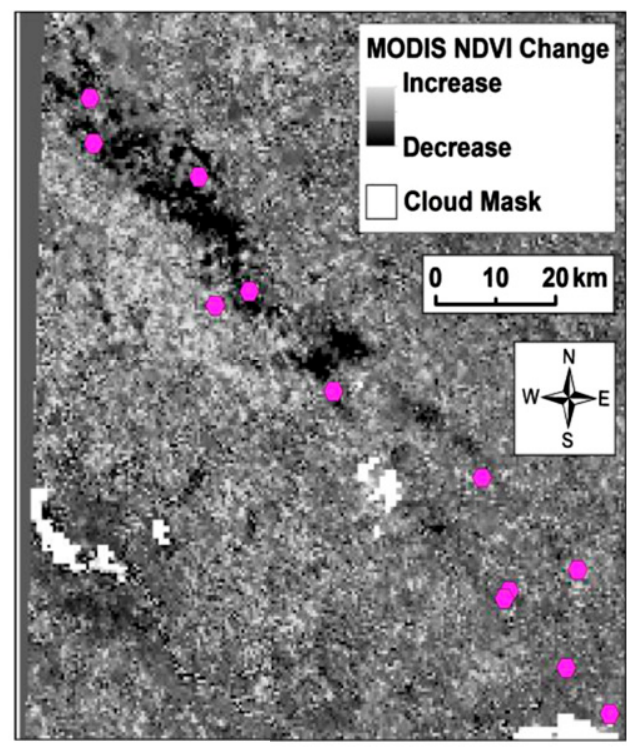

(d)

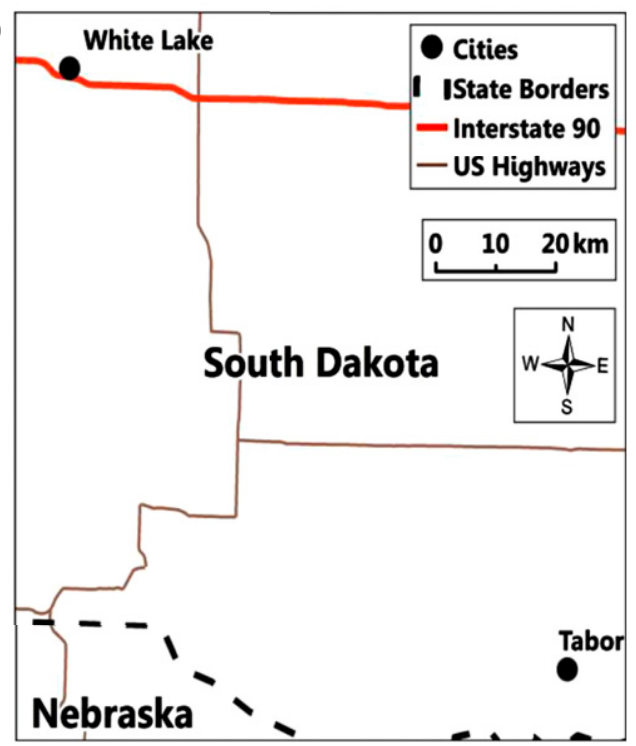

FIG. 3. As in Fig. 1, but for the 26 Jul 2014 event. The nominal NDVI change values for this event ranged from -0.34 (lower $1 \%$ threshold value) to 0.20 (upper $99 \%$ threshold value).

surface reflectance data to exclude potentially cloudcontaminated data from the analysis.

The acquisition dates included in the analysis for each hail event are included in Table 1. Dates selected were based on date of the hail event as well as an initial visual examination of images for cloud contamination. Satellite images prior to the hail event were optimally selected on the date closest to the hail event to represent the vegetation condition prior to the date of the event. Satellite images selected after the event were selected at least 7 days after the event. The delay in postevent data assessment was based on results reported in
Parker et al. (2005), in which the satellite-estimated damage area was found to increase after the initial postevent assessment was made, and preliminary (unpublished) assessment of postevent satellite images of storm damage by the authors. After some severe events that occur

TABLE 1. Dates of hail events and pre- and postevent satellite image acquisition dates of data utilized to compute $\Delta$ NDVI values.

\begin{tabular}{llll}
\hline \hline Event date & 3 Jun 2014 & 9 Jul 2014 & 26 Jul 2014 \\
Pre-event image date & 18 May 2014 & 3 Jul 2014 & 23 Jul 2014 \\
Postevent image date & 20 Jun 2014 & 27 Jul 2014 & 13 Aug 2014 \\
\hline
\end{tabular}


TABLE 2. Dates of hail events and surveys that included photographic imagery and assessment of vegetation condition. Number of spatially coincident satellite and photographic image data samples included the analysis.

\begin{tabular}{llll}
\hline \hline Event date & 3 Jun 2014 & 9 Jul 2014 & 26 Jul 2014 \\
Photographic imagery & 10 and 12 Jun 2014 & 4 and 5 Aug 2014 & 31 Jul and 4 Aug 2014 \\
$\begin{array}{l}\text { Coincident satellite and } \\
\text { photographic data }\end{array}$ & 206 & 219 & 132 \\
\hline
\end{tabular}

early in the growing season, fields may be cleared of debris and replanted. In those cases, a decreased postevent NDVI value would be expected, as bare ground would replace whatever green vegetation might have been present.

The NDVI (Rouse et al. 1974) is defined as the difference in near-IR and visible red band reflectance data divided by the sum of the reflectance from these two bands as

$$
\mathrm{NDVI}=(\mathrm{NIR}-\mathrm{RED}) /(\mathrm{NIR}+\mathrm{RED})
$$

where RED and NIR are the daily MODIS MOD09GA product surface reflectance values in the visible red (620-670 $\mu \mathrm{m})$ and near-IR $(841-876 \mu \mathrm{m})$ bands.

The NDVI change ( $\triangle$ NDVI) between post- and preevent observations were computed from the MODIS data for each event as

$$
\Delta \mathrm{NDVI}=\mathrm{NDVI}_{\text {post-event }}-\mathrm{NDVI}_{\text {pre-event }} .
$$

In addition to the MODIS surface reflectance product the MODIS land cover type product (MCD12Q1, version 006) for 2014 was acquired (LPDAAC 2018) to verify land cover types throughout the regions of each event. The International Geosphere-Biosphere Programme (IGBP) land cover classification (Loveland and Belward 1997) available in the MCD12Q1 product was used for the analysis of land cover classes, as it included the primary (e.g., cropland and grassland) classes in the regions of the examined events. The land cover data, similar to the MODIS surface reflectance data, were obtained through the LPDAAC's AppEEARS web service.

\section{c. Digital photographs and crop damage assessment}

A field survey of the storm event damage was completed between 5 and 27 days after each storm event (Table 2). The field survey included the acquisition of digital photographs, and recorded notes related to observed vegetation characteristics, primarily corn and soybean fields. The NWS Damage Assessment Toolkit (DAT) was used in the acquisition of the field survey digital photographs and ancillary information. Although designed for documentation of tornado damage assessments (e.g., Burgess et al. 2014; Fricker et al. 2014), the
DAT was adapted for use in hail damage assessment. The latitude and longitude values were automatically recorded within the DAT as digital photographs were acquired. The number of samples that included coincident satellite observations and digital photographs ranged from 132 to 219 samples (Table 2). The photographs were classified into one of three levels of vegetation damage: No, Moderate, and Severe Damage (defined in Table 3 and displayed in Fig. 4). The damage levels were selected based on a review of the digital photographs and the ability to discern damage from the photographs. The damage level was assigned through an initial independent assessment of the photographs by three of the authors, followed by a consensus among these individuals. Initial damage thresholds included another level of damage, Minor Damage, that included less than $25 \%$ of leaves lost or brown vegetation (other categories remained similar as described in Table 3 ). However, during review of the digital photographs the consistency of this threshold was determined to be unreliable based on the independent assessments of the photographs.

\section{d. Statistical analyses}

The $\Delta$ NDVI values and coincident photographic observations of vegetation damage levels were analyzed using a consistent geographic coordinate system (WGS84). Data analyses for each of the events initially included tests for normality of the data (Shapiro-Wilk test; SAS 2017a) that resulted in the use of nonparametric tests (KruskalWallis test; SAS 2017b) for significance of differences in median $\triangle$ NDVI values due to observed levels of vegetation damage. Additional pairwise comparisons were

TABLE 3. Levels of vegetation damage assigned to the photographic images of the examined hail events. Abbreviated category names are in italics.

\begin{tabular}{lc}
\hline Damage level & Damage criteria \\
\hline No & No damage visible to vegetation \\
Moderate & Moderate damage $(\leq 90 \%$ of leaves lost or \\
& $\leq 90 \%$ stalks damaged or $\leq 90 \%$ \\
& browning of vegetation $)$ \\
Severe & Severe damage to green vegetation \\
& $(>90 \%$ leaves lost or $>90 \%$ stalks \\
& broken or $>90 \%$ brown vegetation $)$ \\
\hline
\end{tabular}




\section{No Damage: No visible damage to vegetation}
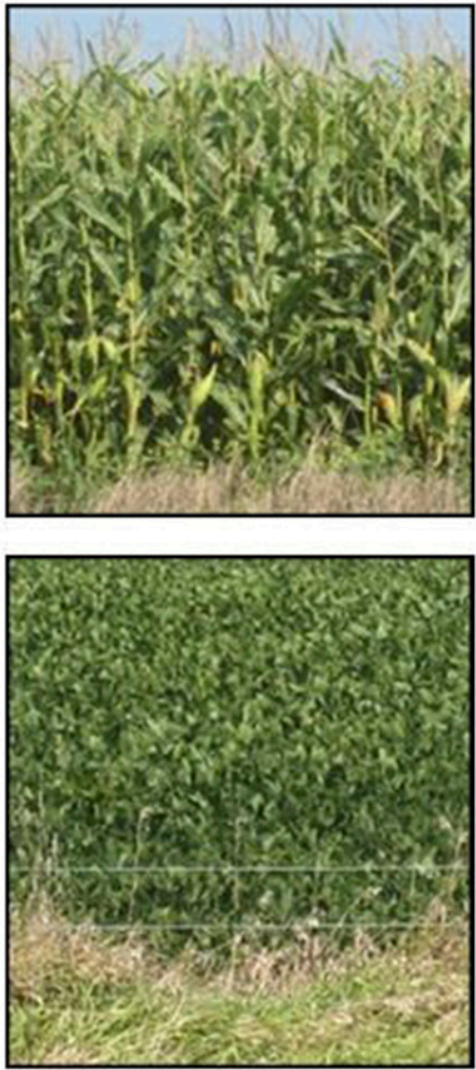

Moderate Damage: $\leq 90 \%$ of leaves lost or $\leq 90 \%$ stalks damaged or $\leq 90 \%$ browning of vegetation
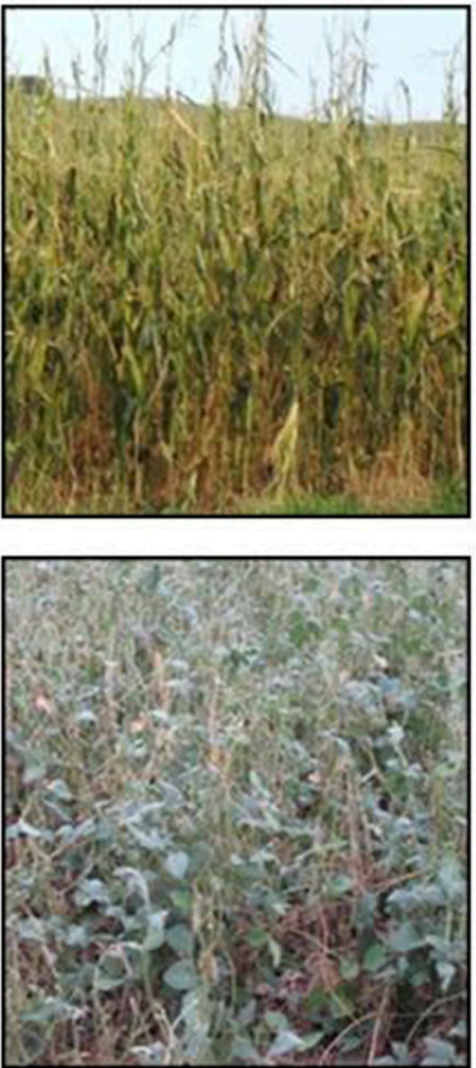

Severe Damage: $>90 \%$ leaves lost or $>90 \%$ stalks broken or $>90 \%$ brown vegetation
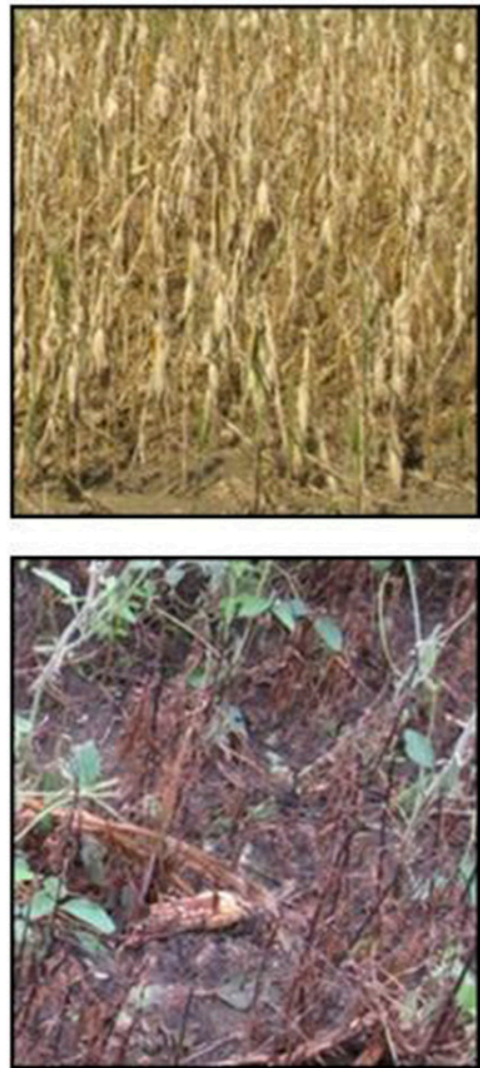

FIG. 4. Digital photograph examples of the three levels of vegetation damage (No, Moderate, and Severe Damage) for (top) corn and (bottom) soybeans.

made when appropriate using the Dwass-Steel-CritchlowFligner multiple comparison analysis (SAS 2017b). A probability level of $0.1(p \leq 0.1)$ was used in all analyses for determination of statistical significance of analysis, and rejection of the null hypothesis that the median $\Delta$ NDVI values did not differ among the various levels of damage.

\section{Results}

The results from the analysis of $\Delta$ NDVI values, compared to vegetation damage, generally indicated that as the damage severity level increased there were decreasing $\triangle$ NDVI values.

\section{a. 3 June 2014 event}

The MODIS $\triangle$ NDVI values associated with this event indicated that as severity of damage to vegetation increased, a decrease was observed in $\triangle$ NDVI (Table 4). The median MODIS $\Delta$ NDVI values ranged from 0.26 for the No Damage level of vegetation damage to 0.04 for the Severe Damage level. At this time of year, and early stage of crop development in this region, the greatest $\triangle$ NDVI values were positive increases in NDVI observed for the vegetation designated with No Damage (Table 4, Figs. 5a, 6a). This increase in NDVI, within areas of no hail damage, is a result of the normal growth and development in vegetation associated with the predominant land cover (agricultural crops) in this region. As damage level increased, the observed pre- and

TABLE 4. Median $\triangle$ NDVI values observed for the three levels of vegetation damage for each of the events included in the study. The $\Delta$ NDVI values observed between each level of damage were significantly different for each event $(p \leq 0.1)$.

\begin{tabular}{lccc}
\hline \hline Event date & No Damage & Moderate Damage & Severe Damage \\
\hline 3 Jun 2014 & 0.26 & 0.13 & 0.04 \\
9 Jul 2014 & -0.07 & -0.21 & -0.35 \\
26 Jul 2014 & 0.02 & -0.10 & -0.18 \\
\hline
\end{tabular}


(a)

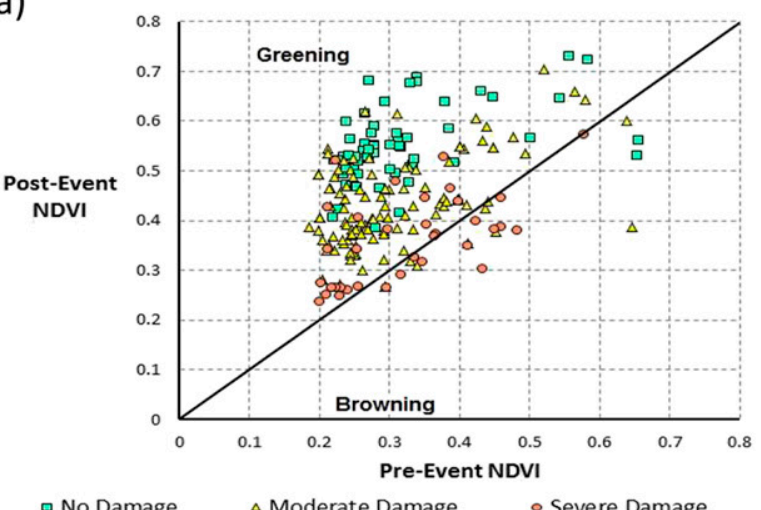

$\square$ No Damage $\quad \triangle$ Moderate Damage $\quad$ Severe Damage

(b)

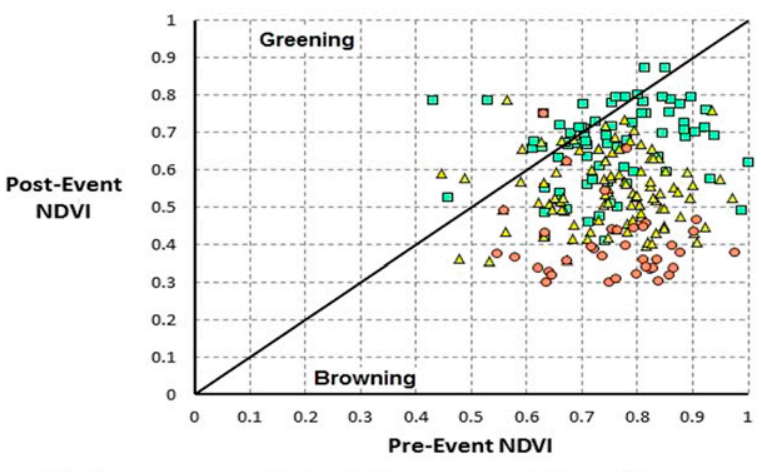

- No Damage $\quad \Delta$ Moderate Damage $\quad$ Severe Damage

(c)

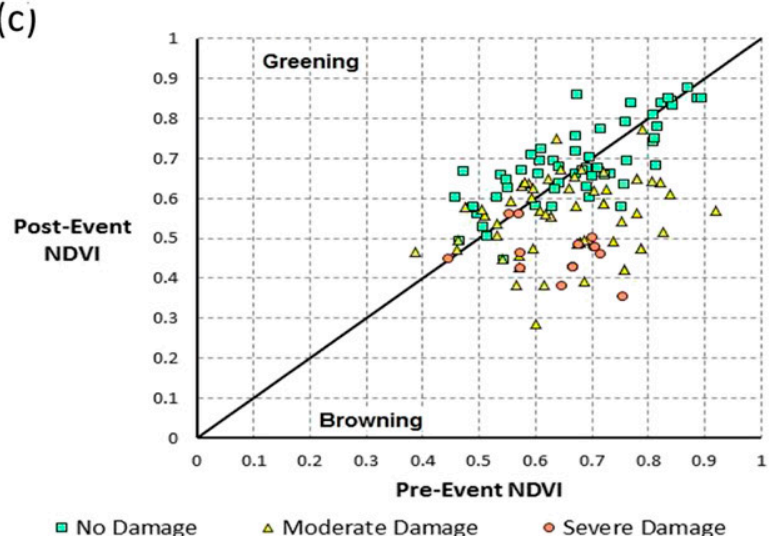

FIG. 5. Post- and pre-event NDVI values for locations of digital photograph observations, with damage levels indicated, for the (a) 3 Jun, (b) 9 Jul, and (c) 26 Jul 2014 events.

postevent NDVI displayed greater similarity (Fig. 5a), or smaller magnitude of change, as indicated by proximity of data to the 1:1 line within the figure. Even the vegetation of this event that was designated as Severe Damage displayed a positive $\Delta$ NDVI (Table 4, Fig. 6a), as there was some regrowth of green vegetation after the damage associated with the event. Bell and Molthan (2016) observed similar results for vegetation response
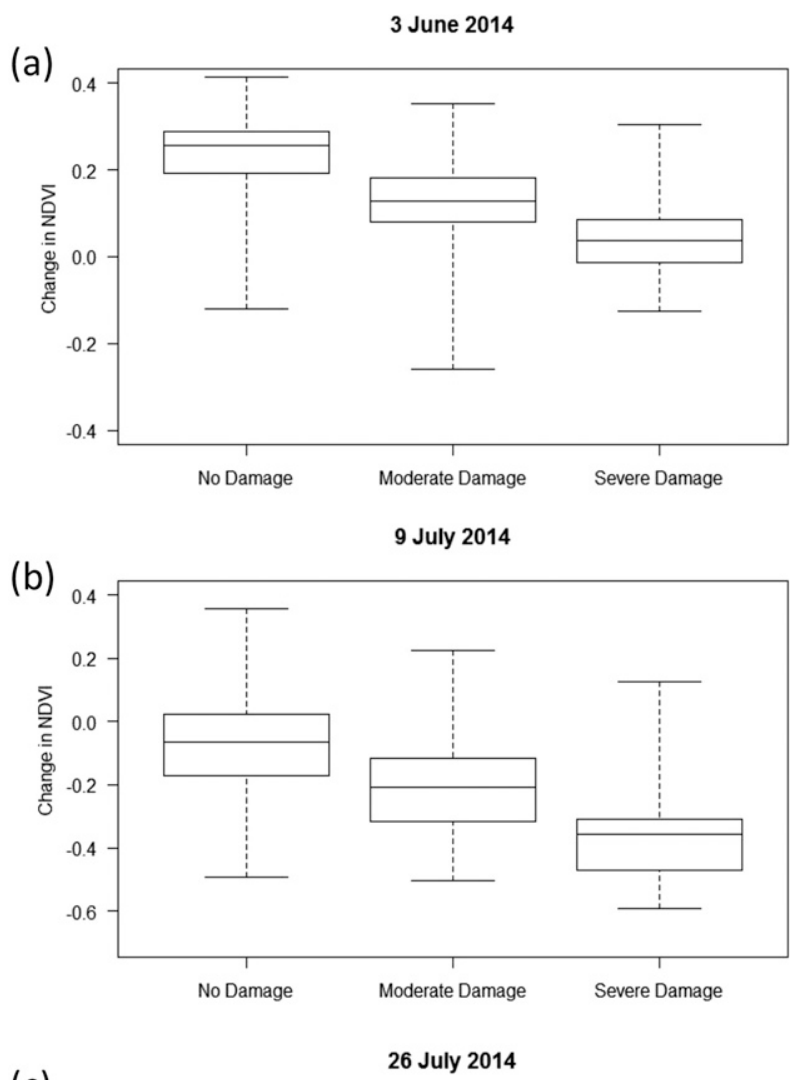

(c)

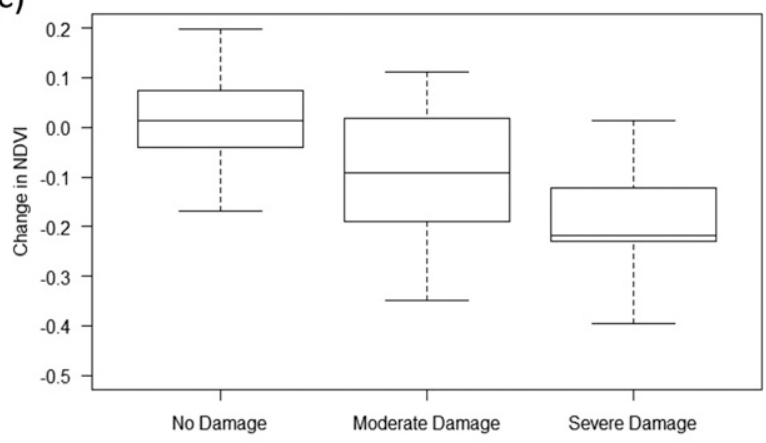

FIG. 6. Boxplots of observed $\triangle$ NDVI for the MODIS sensor for the three levels of vegetation damage of the (a) 3 Jun, (b) 9 Jul, and (c) $26 \mathrm{Jul} 2014$ events. Top and bottom horizontal lines indicate maximum and minimum values, respectively. The top and bottom of the box indicate 75 th and 25 th percentiles, respectively, and the middle line within the box indicates the median value.

after an early growing season event on this same date in another region of southeastern Nebraska.

The results of the statistical analyses indicated that significant differences in the $\triangle$ NDVI values were associated with the damage levels. A pairwise comparison of each of the three damage levels indicated significant differences in $\triangle$ NDVI values for each level of damage (Table 4). 


\section{b. 9 July 2014 event}

The results for the 9 July 2014 hail event, due to the stage of crop development, were similar to those observed for the 9 August 2009 event reported by Gallo et al. (2012), which included greater decreases in $\Delta$ NDVI values with increased vegetation damage within fields that included well-established vegetation. Both corn and soybean crops fully covered the underlying soil at the time of these events, such that the pre-event NDVI presented a relatively large contrast to the postevent NDVI within the vicinity of hail damage. Due to damage or loss of overlying leaves, as a result of the hail event, the postevent NDVI included observations of bare soil that greatly lowered the postevent values compared to pre-event values (Fig. 5b), resulting in a negative $\Delta$ NDVI value (Table 4, Fig. $6 \mathrm{~b}$ ).

The median $\triangle$ NDVI for the MODIS data ranged from -0.07 for the No Damage level to -0.35 for the Severe Damage level (Table 4, Fig. 6b). The observed decrease in NDVI for the No Damage level is attributed to abnormally dry conditions that began in the region between the pre- and postsatellite image observation dates as indicated in the U.S Drought Monitor (https:// droughtmonitor.unl.edu/Maps/MapArchive.aspx) and the vegetation drought response index (VegDRI; https:// www.usgs.gov/land-resources/eros/droughtstress/). The pairwise comparison of each of the three damage levels indicated statistically significant differences in $\triangle$ NDVI values between each level of damage (Table 4).

\section{c. 26 July 2014 event}

The 26 July 2014 event, like the 9 July 2014 event, also resulted in damage primarily to fields that included wellestablished vegetation. At this stage of development, the corn and soybean crops fully covered the underlying soil such that the pre-event NDVI presented a relatively large contrast to the postevent NDVI within the vicinity of hail damage. The pre-event compared to postevent NDVI values for the locations of Moderate and Severe Damage lie predominantly below the 1:1 line (Fig. 5c), indicating a negative $\triangle$ NDVI for these damage levels.

The median $\Delta$ NDVI for the MODIS data ranged from 0.02 for the No Damage level to -0.18 for the Severe Damage level (Table 4, Fig. 6c). Similar to the 3 June and 9 July 2014 events, the pairwise comparison of each of the three damage levels indicated statistically significant differences in $\triangle$ NDVI values between each level of damage (Table 4).

\section{d. Land cover influence on $\triangle N D V I$}

While the damage surveys of digital photographs were limited to croplands, during the surveys of the 9 and 26 July 2014 events the land use was occasionally noted as a mixture of agricultural crops and grassland (e.g., Fig. 7).

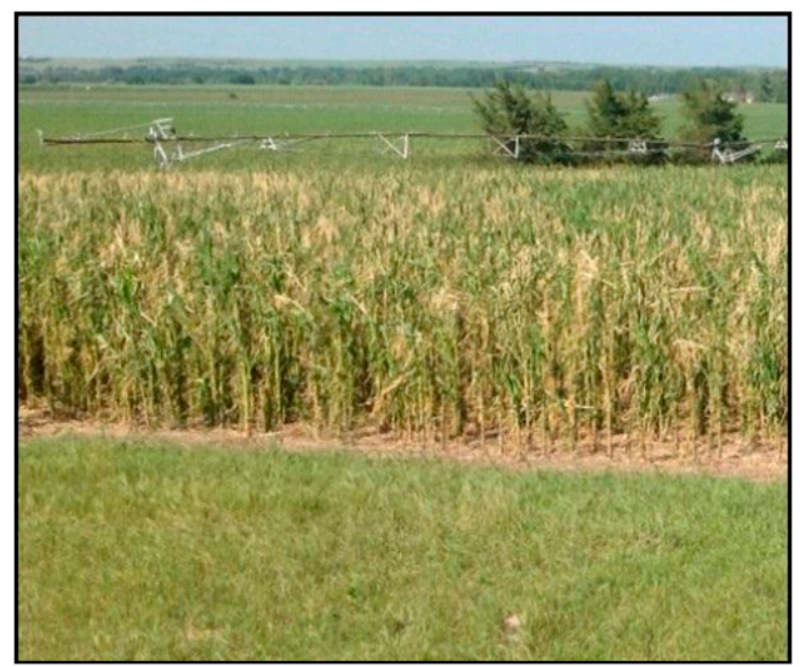

FIG. 7. Example of a damaged corn crop with undamaged grassland in foreground from the digital photograph survey associated with 9 Jul 2014 event in south-central Nebraska.

Additionally, several surveyed locations displayed undamaged grassland adjacent to agricultural fields that exhibited Moderate and Severe Damage levels. As a result of the presence of grassland and cropland associated with these events, the 500-m MODIS pixels occasionally would be expected to include a mixture of crops and grassland, which could result in observed $\Delta$ NDVI that was dependent on the primary land cover (grassland or cropland).

The assessment of the MODIS land cover product for the three events included in this study determined that all of the surveyed sample locations of the 3 June 2014 event were identified as predominantly cropland. However, 24 of the 219 surveyed locations (11\%) of the 9 July 2014 event and 27 of the 132 surveyed locations (20\%) of the 26 July 2014 event were identified as predominantly grassland.

Comparisons of the $\triangle$ NDVI values for the three damage levels of the 9 July 2014 event indicated no statistically significant differences between the land covers identified as predominantly cropland (median $=-0.07$ ) and grassland $(-0.06)$ for the No Damage level. As previously mentioned in section $3 b$, the onset of abnormally dry conditions may have influenced the observed decrease in $\triangle$ NDVI for both land covers. A significant difference was observed at the Moderate Damage level, where the median $\Delta$ NDVI for the sample locations identified as predominantly cropland was -0.23 , while the median grassland value was -0.12 . Differences for the Severe Damage level could not be determined, as only one grassland sample location was available.

The results from the 26 July 2014 event indicated statistically significant differences at the No Damage 
TABLE 5. Difference in median $\triangle$ NDVI values between the three levels of vegetation damage for each of the dates included in the study.

\begin{tabular}{lccc}
\hline \hline Event date & $\begin{array}{c}\text { No Damage to } \\
\text { Moderate Damage }\end{array}$ & $\begin{array}{c}\text { Moderate Damage } \\
\text { to Severe Damage }\end{array}$ & $\begin{array}{c}\text { No Damage to } \\
\text { Severe Damage }\end{array}$ \\
\hline 3 Jun 2014 & -0.13 & -0.09 & -0.22 \\
9 Jul 2014 & -0.14 & -0.14 & -0.28 \\
26 Jul 2014 & -0.12 & -0.08 & -0.20 \\
\hline
\end{tabular}

level, as the predominantly grassland $\triangle$ NDVI increased 0.07 , while the cropland value was unchanged. Significant differences were also indicated at the Moderate Damage level where the grassland $\triangle$ NDVI increased by 0.01 , while the cropland value decreased by -0.11 . No significant difference was indicated at the Severe Damage level, where $\triangle$ NDVI decreased for both the grassland $(-0.18)$ and cropland $(-0.23)$ sampled damage locations.

\section{Discussion}

The challenge associated with reliance on observer reports to represent the spatial area of storm event damage for each of the three storms included in this study (Figs. 1b, 2b, 3b) was similar to the findings of Gallo et al. (2012). Within each of the events examined in this study as the damage level increased from No Damage to Severe Damage, there was a relative decrease in $\triangle$ NDVI values. There were relatively large $\left(>15 \mathrm{~km}^{2}\right)$ spatial areas with damage indicated by relatively decreased $\Delta$ NDVI values (Figs. 1a, 2a, 3a), and verified with digital photographs (Figs. 1c, 2c, 3c), that did not include any observer reports within the Storm Events Database (Figs. 1b, 2b, 3b).

The results of this study are consistent with other studies that have found that satellite- derived indices were useful for assessment of hail damage to green vegetation (e.g., Gallo et al. 2012; Molthan et al. 2013; Bell and Molthan 2016). The photographic images and visual assessment of damage levels within this study provided a unique tool to evaluate the utility of the NDVI to identify spatial areas and assess the level of damage that resulted from hail events.

Within this study, the pre- and postevent changes in the satellite indices were statistically different between the three levels of vegetation damage for the three events examined. However, the influence of the time of year and development stage of the vegetation on the $\Delta$ NDVI values associated with levels of vegetation damage is evident. When the $\Delta$ NDVI values associated with the levels of vegetation damage are compared among the three events studied, there is little consistency in the median $\triangle$ NDVI values associated with a specific level of damage (Table 4). However, as the damage level increased from No Damage to Severe Damage, the postevent NDVI in damaged areas was less than the postevent NDVI in undamaged areas, which resulted in decreased $\triangle$ NDVI values with increasing damage severity. A review of the difference in $\triangle$ NDVI among the three damage levels, the rate of change in $\Delta$ NDVI with increased level of damage, reveals a greater consistency between the events (Table 5, Fig. 8). The rate of change in median $\Delta$ NDVI values between No and Moderate Damage levels ranged from -0.12 to -0.14 among the three events. The rate of change in $\triangle$ NDVI between Moderate and Severe Damage levels ranged from -0.08 to -0.14 and ranged from -0.2 to -0.28 between the No and Severe Damage levels.

\section{Conclusions}

Similar to other studies that have examined storm damage, the temporal change in the difference between post- and pre-event satellite-derived NDVI values were observed to decrease with greater levels of storm event damage. The post- and pre-event satellite-derived NDVI values were statistically different between the three levels of vegetation damage identified through digital

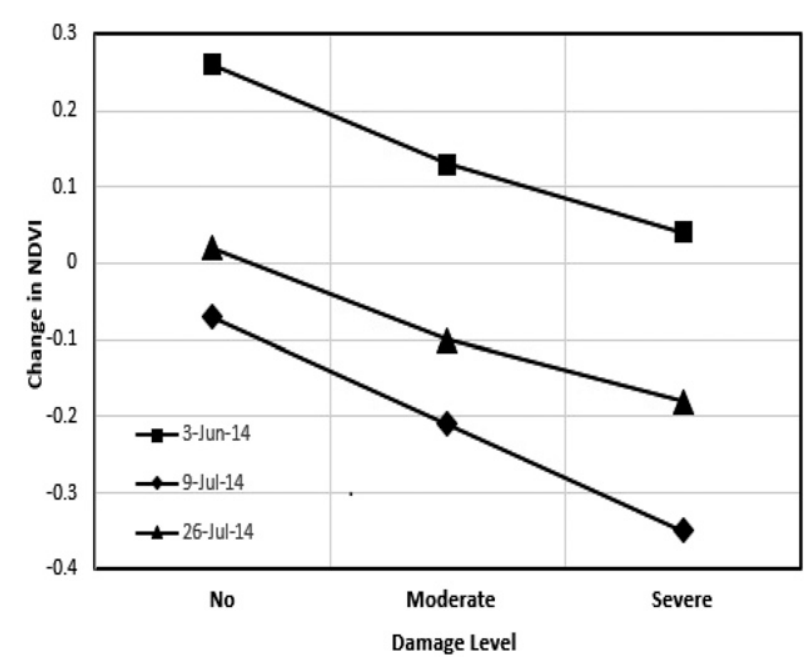

FIG. 8. Median change of NDVI for the three levels of vegetation damage (No, Moderate, and Severe Damage) for the three events included in this study. 
photographs for each of the three events examined. Additionally, the rate of decrease in NDVI associated with the storm damage was similar for the three events. Thus, satellite-derived indices appear to be a valuable tool for assessing the magnitude of the damage to agricultural crops and could provide supplemental information to the currently available point-based observations of storm damage.

Alternative methods for the evaluation of damage from hail events that utilize satellite-derived data have been proposed. Bell and Molthan (2016) examined both NDVI and land surface temperature (LST) changes for similar vegetation types, within and outside of areas of damage, for only postevent dates. This method is certainly worth additional consideration where accurate information exists on the vegetation types within the area of study. Additionally, with the launch of the GOES-R series of satellites that include the Advanced Baseline Imager (Schmit et al. 2017), the availability of NDVI and LST at 5-min intervals will likely provide significant modifications to the current methodologies used for assessment of the land cover changes associated with hail (and tornadic) events.

We recommend future studies that examine additional satellites and sensors that include visible and near-IR data \{e.g., Landsat [Operational Land Imager (OLI), https://www.usgs.gov/land-resources/nli/landsat/landsat-8], Sentinel-2 [Multispectral Instrument (MSI), https:// earth.esa.int/web/sentinel/user-guides/sentinel-2-msi] and Sentinel-3 [Ocean and Land Color Instrument (OLCI), https://sentinel.esa.int/web/sentinel/user-guides/ sentinel-3-olci], $S$-NPP and Joint Polar Satellite System (VIIRS, https://ncc.nesdis.noaa.gov/VIIRS/), GOES-R series [Advanced Baseline Imager (ABI), https://www. goes-r.gov/spacesegment/abi.html]\} and synthetic aperture radar data (e.g., Sentinel-1, https://earth.esa.int/web/ sentinel/user-guides/sentinel-1-sar) for potential use in assessing hail event damage to vegetation. Unmanned aerial vehicles may also provide valuable information about crop or vegetation condition (e.g., Gowravaram et al. 2019). Studies that include assessments of additional satellite-derived indicators of vegetation condition, as well as assessments of hail damage to additional vegetation land cover types (e.g., additional crop types, shrubs, and forests) are also recommended.

Studies that utilize digital photographs should include surveys of vegetation condition at the locations of observer reports that are included in the Storm Events Database for comparison with observations of hail size. Additionally, radar-derived MESH data, which provides gridded estimates of hail size (Smith et al. 2016; NOAA 2018f), should be retrieved shortly after a storm event for comparisons with satellite and photographic images (instructions for data retrieval are available at https://www.nssl.noaa.gov/projects/mrms/ MRMS_data.php). A current limitation associated with the MESH data, however, is that the data are only stored briefly, approximately $24 \mathrm{~h}$, thus data retrieval is required soon after occurrence of an event. The establishment of a dedicated archive of this valuable dataset is recommended.

The NWS DAT currently includes options for designating tornado and wind as potential causes of damage. As noted in section 1, hail causes billions of dollars of damage annually within the United States. As shown in this study, the damage can occur over large swaths similar to downbursts or tornadoes. Given the large amount of damage that can occur with the type of hail storms described in the paper, the addition of hail or wind-driven hail to the DAT as an optional damage category is recommended. This addition will allow the NWS staff to provide a more comprehensive assessment of significant hail damage, including photographs, which would not only be available in Storm Data but also to NWS partners, such as emergency managers or state officials. Inclusion of hail damage in the DAT would facilitate utilization of the damage survey information from a destructive hail storm for a disaster declaration or other type of request for state or federal assistance.

Acknowledgments. The authors thank Ryan Connelly and Marc Chenard for participating on the surveys of hail damage for the 9 and 26 July 2014 hail events, and the LPDAAC staff for assistance with cloud data associated with the MOD09GA product. This study was partially supported by a GOES-R Risk Reduction Program (Project 275). The manuscript's contents do not constitute a statement of policy, decision, or position on behalf of NOAA or the U.S. Government.

\section{REFERENCES}

AppEEARS, 2018: Application for extracting and exploring analysis ready samples. Accessed 29 January 2018, https:// lpdaac.usgs.gov/tools/appeears/.

Bell, J. R., and A. L. Molthan, 2016: Evaluation of approaches to identifying hail damage to crop vegetation using satellite imagery. J. Oper. Meteor., 4, 142-159, https://doi.org/10.15191/ nwajom.2016.0411.

Bentley, M. L., T. L. Mote, and P. Thebpanya, 2002: Using Landsat to identify thunderstorm damage in agricultural regions. Bull. Amer. Meteor. Soc., 83, 363-376, https://doi.org/10.1175/15200477-83.3.363.

Blair, S. F., and Coauthors, 2017: High-resolution hail observations: Implications for NWS warning operations. Wea. Forecasting, 32, 1101-1119, https://doi.org/10.1175/WAF-D-16-0203.1.

Burgess, D., and Coauthors, 2014: 20 May 2013 Moore, Oklahoma, tornado: Damage survey and analysis. Wea. Forecasting, 29, 1229-1237, https://doi.org/10.1175/WAF-D-14-00039.1. 
Changnon, S. A., D. Changnon, and S. D. Hilberg, 2009: Hailstorms across the nation: An atlas about hail and its damages. Illinois State Water Survey Rep., 92 pp.

Cintineo, J. L., T. M. Smith, V. Lakshmanan, H. E. Brooks, and K. L. Ortega, 2012: An objective high-resolution hail climatology of the contiguous United States. Wea. Forecasting, 27, 1235-1248, https://doi.org/10.1175/WAF-D-11-00151.1.

Fricker, T., J. B. Elsner, P. Camp, and T. H. Jagger, 2014: Empirical estimates of kinetic energy from some recent U.S. tornadoes. Geophys. Res. Lett., 41, 4340-4346, https://doi.org/10.1002/ 2014GL060441.

Gallo, K., T. Smith, K. Jungbluth, and P. Schumacher, 2012: Hail swaths observed from satellite data and their relation to radar and surface-based observations: A case study from Iowa in 2009. Wea. Forecasting, 27, 796-802, https://doi.org/10.1175/ WAF-D-11-00118.1.

Gowravaram, S., H. Chao, A. L. Molthan, L. A. Schultz, J. R. Bell, P. Tian, and H. Flanagan, 2019: Evaluating the 22 June 2017 South Dakota hail damage using KHawk UAS: Accuracy quantification and cross validation with satellite imagery. Special Symp. on Meteorological Observations and Instrumentation, Phoenix, AZ, Amer. Meteor. Soc., 2.6, https:// ams.confex.com/ams/2019Annual/webprogram/Paper351427.html.

Jedlovec, G. J., U. Nair, and S. L. Haines, 2006: Detection of storm damage tracks with EOS data. Wea. Forecasting, 21, 249-267, https://doi.org/10.1175/WAF923.1.

Kingfield, D. M., and K. M. de Beurs, 2017: Landsat identification of tornado damage by land cover and an evaluation of damage recovery in forests. J. Appl. Meteor. Climatol., 56, 965-987, https://doi.org/10.1175/JAMC-D-16-0228.1.

Klimowski, B. A., M. R. Hjelmfelt, M. J. Bunkers, D. Sedlacek, and L. R. Johnson, 1998: Hailstorm damage observed from the GOES-8 satellite: The 5-6 July 1996 Butte-Meade storm. Mon. Wea. Rev., 126, 831-834, https://doi.org/10.1175/15200493(1998)126<0831:HDOFTG > 2.0.CO;2.

Loveland, T. R., and A. S. Belward, 1997: The IGBP-DIS global 1km land cover data set, DISCover: First results. Int. J. Remote Sens., 18, 3289-3295, https://doi.org/10.1080/014311697217099.

LPDAAC, 2018: Land Processes Distributed Active Archive Center. Accessed 29 January 2018, https://lpdaac.usgs.gov/.

Molthan, A. L., J. E. Burks, K. M. McGrath, and F. J. LaFontaine, 2013: Multi-sensor examination of hail damage swaths for near real-time applications and assessment. J. Oper. Meteor., 1, 144-156, https://doi.org/10.15191/nwajom.2013.0113.

— J. R. Bell, T. A. Cole, and J. E. Burks, 2014: Satellite-based identification of tornado damage tracks from the 27 April 2011 severe weather outbreak. J. Oper. Meteor., 2, 191-208, https:// doi.org/10.15191/nwajom.2014.0216.

NOAA, 2018a: Summary of natural hazard statistics for 2017 in the United States. Accessed 19 October 2018, http://www.nws.noaa.gov/ om/hazstats/sum17.pdf.

2018b: Natural hazard statistics. Accessed 27 June 2018, http://www.nws.noaa.gov/om/hazstats.shtml.

- 2018c: Storm data. Accessed 29 January 2018, https:// www.ncdc.noaa.gov/IPS/sd/sd.html.

2018d: Storm events database. Accessed 29 January 2018, https://www.ncdc.noaa.gov/stormevents/.
— 2018e: Storm data FAQ page. Accessed 19 October 2018, https://www.ncdc.noaa.gov/stormevents/faq.jsp.

_ 2018f: NOAA Virtual Lab, MRMS product guides. Accessed 29 January 2018, https://vlab.ncep.noaa.gov/web/wdtd/-/ maximum-estimated-size-of-hail-mes-1?selectedFolder $=562123$.

Ortega, K. L., 2018: Evaluating multi-radar, multi-sensor products for surface hail-fall diagnosis. E-J. Severe Storms Meteor., 13 (1) $1-36$

_ T. M. Smith, K. L. Manross, A. G. Kolodziej, K. A. Scharfenberg, A. Witt, and J. J. Gourley, 2009: The Severe Hazards Analysis and Verification Experiment. Bull. Amer. Meteor. Soc., 90, 1519-1530, https://doi.org/10.1175/2009BAMS2815.1.

Parker, M. D., I. C. Ratcliffe, and G. M. Henebry, 2005: The July 2003 Dakota hailswaths: Creation, characteristics, and possible impacts. Mon. Wea. Rev., 133, 1241-1260, https://doi.org/ 10.1175/MWR2914.1.

Rouse, J. W., R. H. Haas, J. A. Schell, and D. W. Deering, 1974: Monitoring Vegetation Systems in the Great Plains with ERTS (Earth Resources Technology Satellite). Proc. Third Earth Resources Technology Satellite Symp., Greenbelt, MD, NASA GSFC, 309-317.

SAS, 2017a: SAS/QC 14.3 user's guide: The CAPABILITY procedure. Accessed 21 June 2018, 373 pp., http://documentation.sas.com/ api/docsets/qcug/14.3/content/capability.pdf?locale $=$ en\#nameddest $=$ qcug_capability_sect042.

_ 2017b: SAS/STAT 14.3 user's guide: The NPAR1WAY procedure. Accessed 2 February 2018, 80 pp., http://documentation.sas.com/api/ docsets/statug/14.3/content/npar1way.pdf?locale $=$ en\#nameddest $=$ statug_npar1way_overview.

Schmit, T. J., P. Griffith, M. M. Gunshor, J. M. Daniels, S. J. Goodman, and W. J. Lebair, 2017: A closer look at the ABI on the GOES-R series. Bull. Amer. Meteor. Soc., 98, 681-698, https://doi.org/10.1175/BAMS-D-15-00230.1.

Segele, Z. T., D. J. Stensrud, I. C. Ratcliffe, and G. M. Henebry, 2005: Influence of a hailstreak on boundary layer evolution. Mon Wea. Rev., 133, 942-960, https://doi.org/10.1175/MWR2897.1.

Smith, T. M., and Coauthors, 2016: Multi-Radar Multi-Sensor (MRMS) severe weather and aviation products: Initial operating capabilities. Bull. Amer. Meteor. Soc., 97, 1617-1630, https://doi.org/10.1175/BAMS-D-14-00173.1.

Stout, G. E., R. Blackmer, and K. E. Wilk, 1960: Hail studies on Illinois relating to cloud physics. Physics of Precipitation, Geophys. Monogr., Vol. 5, Amer. Geophys. Union, 369-381.

Witt, A., M. D. Eilts, G. J. Stumpf, J. T. Johnson, E. D. Mitchell, and K. W. Thomas, 1998a: An enhanced hail detection algorithm for the WSR-88D. Wea. Forecasting, 13, 286-303, https:// doi.org/10.1175/1520-0434(1998)013<0286:AEHDAF>2.0.CO;2.

,,--- E. D. Mitchell, J. T. Johnson, and K. W. Thomas, 1998b: Evaluating the performance of WSR-88D severe storm detection algorithms. Wea. Forecasting, 13, 513-518, https:// doi.org/10.1175/1520-0434(1998)013<0513:ETPOWS>2.0.CO;2.

Yuan, M., M. Dickens-Micozzi, and M. Magsig, 2002: Analysis of tornado damage tracks from the 3 May tornado outbreak using multispectral satellite imagery. Wea. Forecasting, 17, 382-398, https://doi.org/10.1175/1520-0434(2002)017<0382: AOTDTF $>2.0 . \mathrm{CO} ; 2$. 